\title{
Characterisation of monoclonal antibodies for detection of Mobiluncus spp. in genital specimens
}

\author{
C. A. ISON, B. KOLATOR，J.H. REID*, E. DERMOTTt, J. CLARK* and C.S. F. EASMON \\ Department of Medical Microbiology, Wright-Fleming Institute, St Mary's Hospital MedicalSchool, Paddington, \\ London W2 1PG, *Coralab Research, Huntingdon Road, Cambridge, and tDepartment of Microbiology and \\ Immunobiology, The Queen's University of Belfast, Grosvenor Road, Belfast BT12 6BN
}

\begin{abstract}
Summary. Monoclonal antibodies were raised to the anaerobic curved rods, Mobiluncus curtisii subsp. curtisii NCTC 11656, $M$. curtisii subsp. holmesii NCTC 11657 and $M$. mulieris NCTC 11658. Three antibodies reacted with the two subspecies of $M$. curtisii and, when used in combination against clinical isolates, showed $100 \%$ sensitivity and specificity in immunofluorescence studies. Immunoblotting showed that two of these antibodies reacted with an epitope on a protein which had an electrophoretic mobility corresponding to a $\mathrm{Mr}$ of $75 \mathrm{Kda}$ in the absence of a reducing agent and $82 \mathrm{Kda}$ in its presence in both type strains and in clinical isolates. The third antibody reacted with an epitope in type strains which had a mobility corresponding to $75 \mathrm{Kda}$ and was unaffected by a reducing agent. However, in clinical isolates the epitope was present on a protein of $75 \mathrm{Kda}$ or $71 \mathrm{Kda}$, or on both. A fourth antibody showed reactivity with $M$. mulieris NCTC 11658 alone, but only $6(24 \%)$ of 25 clinical isolates gave positive results by immunofluorescence. The epitope is believed to be present on a protein of $>90 \mathrm{Kda}$. All four antibodies were shown by immunogold staining to be directed against epitopes exposed on the cell surface.
\end{abstract}

\section{Introduction}

Motile curved bacilli were first described in vaginal secretions by Curtis (1913) and then by Moore (1954) and Durieux and Dublanchet (1980). Spiegel and Roberts (1984) found that these bacilli were distinct from related genera and recommended the creation of a new genus Mobiluncus to include two species-M. mulieris, the long variant and $M$. curtisii the short variant, the latter being further divided into $M$. curtisii subsp. curtisii and subsp. holmesii. Characteristics of the genus include multiple polar flagella, a multilayered gram-variable cell wall, production of succinate and acetate, and a DNA G + C content of $49-52 \mathrm{~mol}^{\%}$.

Anaerobic curved rods, together with Gardnerella vaginalis and Bacteroides spp., have been associated with bacterial vaginosis (Hjelm et al., 1981; Phillips and Taylor, 1982; Skarin and Mardh, 1982; Sprott et al., 1982). However, Mobiluncus spp. are fastidious, slow growing organisms and, in most studies, they have been isolated from only $10-50 \%$ of women with vaginosis (Sprott et al., 1983; Hjelm et al.,

Received 14 Sep. 1988; accepted 21 Feb. 1989.
1984; Hallen et al., 1987). This is in contrast with studies in which the diagnosis was based on microscopy; in these, motile curved rods have been seen in vaginal secretions from up to $90 \%$ of women with vaginosis (Roberts et al., 1985). Using a DNA probe to detect Mobiluncus spp. in vaginal secretions, Roberts et al. (1985) found the organisms in $83 \%$ of women with vaginosis, suggesting that the low figures obtained in previous studies with culture resulted from technical problems. Unlike G. vaginalis and Bacteroides spp., curved motile rods have been reported only rarely in women without vaginosis (Skarin and Mardh, 1982; Spiegel et al., 1983; Sprott et al., 1983). Hallen et al. (1987) used monoclonal antibodies (MAbs) in an immunofluorescence test to detect Mobiluncus spp. in women with bacterial vaginosis. They provided evidence that immunofluorescence was more sensitive than microscopy of wet smears and also showed that Mobiluncus spp. could be detected in a few women who did not have signs of vaginosis. In this paper we describe the characterisation of four MAbs raised against Mobiluncus spp. for their potential use for the detection of Mobiluncus spp. in clinical specimens. 


\section{Materials and methods}

\section{Strains}

The three type strains of Mobiluncus spp. were obtained from the National Collection of Type Cultures, Colindale, London- $M$. curtisii subsp. curtisii NCTC 11656, $M$. curtisii subsp. holmesii NCTC 11657, and M. mulieris NCTC 11658. Seventeen clinical isolates were from our own collection, 20 strains were obtained from Professor I. Phillips, St Thomas's Hospital, London and 25 from Dr M. S. Sprott, Public Health Laboratory, Newcastleupon-Tyne. Of the 62 strains used, 37 were short curved rods and 25 were long curved rods.

Bacteria used to test the specificity of the antibodies in immunofluorescence studies included 9 strains of anaerobic curved rods which did not conform to the definition of Mobiluncus spp. but were not identified further, 10 strains of Neisseria gonorrhoeae, 20 of G. vaginalis, 10 of lactobaccilli, 10 of Group B streptococci, 6 of Haemophilus ducreyi, one of Peptostreptococcus, 8 of Bacteroides bivius, 5 of $B$.disiens, 5 of $B$. melaninogenicus and one of Escherichia coli.

\section{Isolation and identification}

All strains of Mobiluncus spp. were grown on Columbia Agar Base (BBL Microbiology Systems) containing outdated banked human blood $10 \%$ (HBA); cultures were incubated for 3-4 days at $37^{\circ} \mathrm{C}$ in an anaerobic atmosphere generated by an Anaerocult A system without a catalyst (Merck Diagnostic, BDH).

Bacterial strains were identified as Mobiluncus spp. if they were anaerobic, motile, gram-variable curved rods which were resistant to a 5- $\mu \mathrm{g}$ metronidazole disk. The two species were distinguished by the ability to hydrolyse hippurate, reduce nitrate and ferment carbohydrates by the use of methods described previously (Holdeman et al., 1977). Enzyme production was detected with APIZYM (API Laboratories) test strips. Strains were divided into the two species by the criteria described by Spiegel and Roberts (1984).

\section{Production of $M A b s$}

Male BALB/C mice were immunised with formalintreated whole cells of $M$. curtisii subsp. curtisii NCTC 11656, M. curtisii subsp. holmesii NCTC 11657 or $M$. mulieris NCTC 11658. The mice were inoculated intramuscularly with $0.1 \mathrm{ml}$ of a suspension containing $5.0 \times 10^{8} \mathrm{cells} / \mathrm{ml}$ in Freund's incomplete adjuvant and given a booster dose 9 weeks after the first injection. The spleen was removed for fusion 3 days after the last injection.

Spleen cells from the immunised mice were fused with uncloned NSO myleloma cells by the polyethylene glycol fusion method of Galfré and Milstein (1981). Hybridoma cell lines were selected in DMEM (Flow Laboratories) containing hypoxanthine-aminopterin-thymidine and fetal calf serum (Tissue Culture Services) $18 \%$ v/v. Hybrid- oma supernate was screened for antibody production by an indirect ELISA in which whole cells of various strains of Mobiluncus spp., including the immunising strains, were used as antigen. Hybridoma cell lines were cloned at least twice by a limiting dilution method with BALB/C macrophage feeder layers, concentrated and stored at $192^{\circ} \mathrm{C}$ in fetal calf serum $90 \%$ and dimethyl sulphoxide $10 \%$.

A 'capture' ELISA was used to determine the isotype of the MAbs. Sheep anti-mouse IgG2a (Serotec), and goat anti-mouse IgG1, IgG2b, IgG3 and IgM (Sigma) were diluted in $50 \mathrm{~mm}$ sodium carbonate buffer, $\mathrm{pH} 9 \cdot 6$, and coated on to PVC microtitration plates. After incubation with hybridoma culture supernate, goat antimouse IgG (specific for light and heavy chains) conjugated to alkaline phosphatase (Sigma) was added. The substrate used was $p$-nitrophenyl phosphate $1 \mathrm{mg} / \mathrm{ml}$ in $50 \mathrm{~mm}$ carbonate buffer, $\mathrm{pH} 9 \cdot 8$, containing $1 \mathrm{~mm} \mathrm{MgCl}{ }_{2}$, and absorbance was read at $405 \mathrm{~nm}$ after $30 \mathrm{~min}$.

\section{Immunofluoresence microscopy}

The antigen was prepared by growing Mobiluncus strains on $10 \%$ HBA as described above. A thin smear was made on a multispot slide in phosphate buffered saline (PBS), air dried and fixed in methanol $70 \%$. Antibody was diluted in PBS and added to each spot, incubated at $37^{\circ} \mathrm{C}$ for $30 \mathrm{~min}$ and then washed in PBS followed by distilled water. Rabbit anti-mouse immunoglobulin conjugated to FITC (Dakopatts) was added, incubated as before, washed, dried and examined with a Laborlux K microscope (Leitz).

\section{Immunoblotting of SDS-PAGE}

Each Mobiluncus strain was grown on $10 \% \mathrm{HBA}$ for $3-$ 4 days, harvested, washed and suspended in saline. The protein concentration of the suspension was estimated (Lowry et al., 1951) and adjusted to $2 \mathrm{mg} / \mathrm{ml}$. The suspension was diluted in double strength sampling buffer (bromophenol blue $0.1 \%$, sodium dodecyl sulphate $2 \%$, $0.1 \mathrm{~m}$ Tris- $\mathrm{HCl}, \mathrm{pH} 6.8,8 \% \mathrm{v} / \mathrm{v}$ and glycerol $10 \%$ ). Samples of the type strains and the clinical isolates were prepared in the presence and absence of $0.1 \mathrm{M}$ Clelands reagent (Sigma) and solubilised at $100^{\circ} \mathrm{C}$ for $10 \mathrm{~min}$.

The cell lysates were separated by sodium dodecyl sulphate-polyacrylamide gel electrophoresis (SDSPAGE) as described by Laemmli (1970) with either a $10 \%$ (short curved rods) or a $15 \%$ (long curved rods) separating gel and a $5 \%$ stacking gel on a Protean II apparatus(Bio-Rad). Samples containing $10 \mu \mathrm{g}$ of protein were loaded on to the gel with low-mol.-wt standards (Pharmacia) and the gel was run for $2 \mathrm{~h}$ at $30 \mathrm{~mA} / \mathrm{gel}$. Proteins were then transferred to nitrocellulose (Hybond C, Amersham International) electrophorectically in a buffer of $20 \mathrm{~mm}$ Tris, $150 \mathrm{~mm}$ glycine and methanol $20 \%$ in a Trans-Blot apparatus (Bio-Rad Laboratories) with a current of $200 \mathrm{~mA}$ for $2 \mathrm{~h}$ (Towbin et al., 1979). The tracks containing mol.-wt markers were removed and 
stained for protein with amido black $0.1 \%$ in methanol $25 \%$ and acetic acid $10 \%$. The rest of the membrane was then immersed in bovine serum albumin (BSA) $4 \%$ in washing buffer $(0 \cdot 15 \mathrm{~mm}$ sodium chloride, $10 \mathrm{~mm}$ Tris, $\mathrm{pH}$ 7.4) and incubated at $37^{\circ} \mathrm{C}$ for $1 \mathrm{~h}$. All further dilutions or washings were with the same buffer containing BSA $0.1 \%$. Antibody was added at the appropriate dilution ( 1 in 1000 for MAb 180.1 and 1 in 500 for MAbs 179.1, 179.3 and 181.1) and left overnight at $4^{\circ} \mathrm{C}$. After washing, the membranes were incubated with rabbit anti-mouse immunoglobulin conjugated to alkaline phosphatase (Dakopatts) diluted 1 in 3000.

The membranes were washed again and immersed in substrate $(0.75 \mathrm{ml}$ of 5-bromo-4-chloro-3-indolylphosphate, Sigma, $4 \mathrm{mg} / \mathrm{ml}$ in methanol: acetone $2: 1 \mathrm{v}: \mathrm{v}$; $5 \mathrm{ml}$ of nitroblue tetrazolium (Sigma) $1 \mathrm{mg} / \mathrm{ml} ; 0 \cdot 2 \mathrm{ml}$ of $1 \mathrm{M}$ magnesium chloride; $44.05 \mathrm{ml}$ of $0.1 \mathrm{M}$ ethanolamine$\mathrm{HCl}$ buffer, $\mathrm{pH} \mathrm{9.6)} \mathrm{for} 15 \mathrm{~min}$; the reaction was then stopped by rinsing in water.

\section{Immunoblotting of colonies}

Suspensions of the type strains of $M$. curtisii were diluted and inoculated on to $10 \%$ HBA to give individual colonies after incubation for $48 \mathrm{~h}$. Filter paper disks (Whatman) were then placed on each plate and left for a few minutes, removed and allowed to dry completely. The filters were treated with $\mathrm{H}_{2} \mathrm{O}_{2} 1 \%$ in methanol for 30 min to remove inherent bacterial peroxidase. After rinsing twice in distilled water, the filters were immersed in antibody diluted in washing buffer (as before) without the addition of BSA, for $2 \mathrm{~h}$ at $37^{\circ} \mathrm{C}$ on a rotary shaker. After a further three washes rabbit anti-mouse immunoglobulin conjugated to peroxidase (Dakopatts) diluted 1 in 3000 was added for $2 \mathrm{~h}$ as before. The filters were washed again and then immersed in substrate $\left(3,4,3^{\prime}, 4^{\prime}\right.$ tetra-aminobiphenyl hydrochloride, $\mathrm{BDH}, 0.5 \mathrm{mg} / \mathrm{ml}$ in $50 \mathrm{~mm}$ Tris- $\mathrm{HCl}, \mathrm{pH} 7 \cdot 4$, containing $\mathrm{H}_{2} \mathrm{O}_{2} 0.01 \%$ ).

\section{Immunoelectronmicroscopy}

Samples of the organisms in suspension were applied to grids previously coated with formvar/carbon, drained and allowed to dry before being treated with MAb and immunogold (goat anti-mouse IgG conjugated to $25-\mathrm{nm}$ gold colloidal particles; Janssen Life Sciences Products) as follows. Grids were immersed in BSA $1 \% \mathrm{w} / \mathrm{v}$ in $20 \mathrm{~mm}$ Tris-buffered saline, pH 8.2 (BSA-TBS) for $10 \mathrm{~min}$, drained and placed in tissue-culture supernate containing $\mathrm{MAb}$ for $2 \mathrm{~h}$ at room temperature. After thorough washing, grids were again placed in BSA-TBS, then in gold conjugate diluted 1 in 20 in BSA-TBS $0.1 \% \mathrm{w} / \mathrm{v}$ for $2 \mathrm{~h}$ at room temperature, followed by two more washes, first in $20 \mathrm{~mm}$ TBS then distilled water. Control grids were prepared with saline instead of the MAb, followed by labelling with gold conjugate as above. Grids were negatively stained with phosphotungstic acid and allowed to dry before being examined in a Philips 301 transmission electronmicroscope.

\section{Results}

\section{Monoclonal antibodies}

A series of seven MAbs was produced after a single fusion of spleen cells from mice inoculated with each type strain. Four were chosen for further study on the basis of their reactivity when screened against various strains of Mobiluncus and their ability to react in immunofluorescence (IF) studies. The antibodies were designated MAbs 179.1, 179.3, 180.1 and 181.1. The immunoglobulin subclasses of the antibodies were IgG2b (179.1) and IgG1 (179.3, 180.1 and 181.1).

\section{Immunofluorescence}

In IF studies, three of the four MAbs (179.1, 179.3 and 180.1 ) showed activity against the type strains of both subspecies of $M$. curtisii, NCTC 11656 and 11657 , but not against $M$. mulieris NCTC 11658. MAb 179.1 showed equal activity against both subspecies whereas MAbs 179.3 and 180.1 showed activity against both subspecies but at different titres. MAb 179.3 showed a higher titre against $M$. curtisii subsp. holmesii whereas the titre of MAb 180.1 was higher against $\boldsymbol{M}$. curtisii subsp. curtisii. The remaining MAb, 181.1, showed activity against $M$. mulieris NCTC 11658 but not against $M$. curtisii NCTC 11656 or NCTC 11657 . The titres of all antibodies varied between different supernates but an example from twice cloned cells is shown in table I.

A range of clinical isolates was tested to determine the sensitivity of the MAbs, i.e., the number of strains detected. MAbs were used at a dilution of 1 in 4, which was chosen to detect speciesspecific antigens. All 37 strains of $M$. curtisii reacted with one or more of MAbs 179.1, 179.3 and 180.1. Five patterns of reactivity were seen (table II). The

Table I. Titres of supernate against the type strains of Mobiluncus spp. in immunofluorescence (IF) tests

\begin{tabular}{l|ccc}
\hline & \multicolumn{3}{|c}{ IF titres with } \\
\cline { 2 - 3 } & \multicolumn{3}{|c}{$M$. curtisii } \\
\cline { 2 - 4 } MAb & subsp. curtisii & subsp. holmesii & $M$. mulieris \\
& NCTC 11656 & NCTC 11657 & NCTC 11658 \\
\hline 179.1 & 128 & 128 & 0 \\
179.3 & 16 & 32 & 0 \\
180.1 & 512 & 128 & 16 \\
181.1 & 0 & 0 & 0 \\
\hline
\end{tabular}


Table II. Pattern of reactivity of clinical isolates of $M$. curtisii with MAbs 179.1, 179.3 and 180.1

\begin{tabular}{cc|ccc}
\hline & & \multicolumn{3}{|c}{ Reactivity with MAb } \\
\cline { 3 - 5 } Pattern & $\begin{array}{c}\text { Number of } \\
\text { strains }\end{array}$ & $179 \cdot 1$ & $179 \cdot 3$ & $180 \cdot 1$ \\
\hline A & 16 & +++ & +++ & +++ \\
B & 8 & +++ & - & +++ \\
C & 9 & - & - & +++ \\
D & 3 & +++ & +++ & - \\
E & 1 & - & +++ & +++ \\
\hline
\end{tabular}

majority of strains, $34(92 \%)$ of 37 , reacted with MAb 180.1. None of the clinical isolates of $M$. curtisii showed fluorescence with MAb $181 \cdot 1$.

Only $6(24 \%)$ of the 25 clinical isolates of $M$. mulieris tested by IF gave positive reactions. However, even in positive smears only a proportion of cells fluoresced strongly, the remainder being weakly positive or negative. This phenomenon was also seen with the subspecies of $M$. curtisii and MAbs 179.1, 179.3 and 180.1. None of the strains of $M$. mulieris reacted with MAbs $179.1,179.3$ or 180.1 .

The four antibodies were highly specific for the relevant species of Mobiluncus and did not react with any of the other bacterial genera tested.

\section{Immunoblotting of SDS-PAGE}

Immunoblotting was used to characterise the epitope(s) against which these antibodies were directed. The type strains were used in initial experiments and the clinical isolates were compared with these subsequently.

MAbs 179.1 and 179.3 reacted with epitopes in M. curtisii NCTC 11656 and NCTC 11657 on a protein band that had an electrophoretic mobility corresponding to an $\mathrm{Mr}$ of $75 \mathrm{Kda}$ in the absence of a reducing agent but of $82 \mathrm{Kda}$ in its presence. The same pattern was seen with those clinical isolates that gave a positive IF reaction. IF-negative strains showed no band on immunoblotting.

MAb 180.1 reacted with an epitope in both $M$. curtisii type strains on a protein with a mobility corresponding to $75 \mathrm{Kda}$. The $\mathrm{Mr}$ was not affected by a reducing agent. With clinical isolates this antibody reacted with an epitope on a protein of $75 \mathrm{Kda}$ or of $71 \mathrm{Kda}$ or on both (fig. 1). When both proteins were reactive, the amount of epitope expressed by each protein was often unequal. The reaction of each MAb with clinical isolates of $M$. curtisii is summarised in table III.

$\mathrm{MAb} 181.1$ reacted weakly with a protein of c. $90 \mathrm{Kda}$ in $M$. mulieris, but only when the cell lysate was prepared in the absence of a reducing agent. The difficulty of detecting weak antibody

\section{$\begin{array}{llllllllllll}K d a & 1 & 2 & 3 & 4 & 5 & 6 & 7 & 8 & 9 & 10\end{array}$}

94-

$67-$

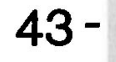

$30-$

Fig. 1. Immunoblot of MAb 180.1 against strains of $M$. curtisii. Tracks 1-8, clinical isolates of $M$. curtisii; track 9, $M$. curtisii NCTC 11657 ; track 10, $M$. curtisii NCTC 11656. 
Table III. Reaction with clinical isolates of $M$. curtisii by immunoblotting

\begin{tabular}{c|cc}
\hline & \multicolumn{2}{|c}{$\begin{array}{c}\text { Mr (Kda) of reactive protein determined by } \\
\text { SDS-PAGE }\end{array}$} \\
\cline { 2 - 3 } $\mathrm{MAb}$ & $\begin{array}{c}\text { with reducing } \\
\text { agent }\end{array}$ & $\begin{array}{c}\text { without reducing } \\
\text { agent }\end{array}$ \\
\hline & + & - \\
179.1 & 82 & 75 \\
179.3 & 82 & 75 \\
& 71 & 71 \\
& 75 & 75 \\
& $71 / 75$ & $71 / 75$ \\
\hline
\end{tabular}

reactions was attributed to the relatively poor transfer of high-mol.-wt proteins in this system. Twelve of the 25 clinical isolates of $M$. mulieris expressed an epitope also on a protein of $90 \mathrm{Kda}$; six of these strains were IF positive and six were IF negative. The antibodies did not cross-react between species of Mobiluncus.

\section{Immunoblotting of colonies}

Immunoblotting was used to determine the degree of expression of the epitope detected by MAb 180.1 by individual colonies of populations of $M$. curtisii NCTC 11656 and NCTC 11657 . Only a proportion of the colonies were labelled strongly; the remainder showed weak or no reactivity, Continued subculture reduced the number of colonies expressing the epitope but this was not a consistent finding.

\section{Immunogold staining}

The staining of the type strains by immunogold spheres showed that all four MAbs detected an epitope exposed on the cell surface (fig. 2). However, as was seen in IF and colony-blotting studies, each MAb detected only a subpopulation of cells. $M$. curtisii exhibited the epitope in a number of ways--bipolar, evenly distributed over the cell, or on one of two daughter cells (fig. 2).

\section{Discussion}

Motile anaerobic curved rods seen in vaginal secretions have proved difficult to isolate and purify because of their fastidious growth requirements and the presence of numerous other anaerobes in the vaginal secretions. We have raised a series of MAbs in an attempt to produce a rapid detection system. To evaluate such reagents it is important to investigate both the sensitivity and specificity. We have tested the sensitivity with a range of organisms which we believe belong to the genus Mobiluncus. When used in combination, the three MAbs directed against $M$. curtisii showed $100 \%$ sensitivity and specificity. Of the 37 clinical strains of $M$. curtisii tested $26(70 \%)$ reduced nitrate. Nitrate reduction and the ability to migrate through soft agar were the two criteria used by Spiegel and Roberts (1984) to distinguish between the subspecies of $M$.curtisii. Our results suggest that the majority of the strains were $M$. curtisii subsp. holmesii but as we did not test for the ability to migrate through soft agar we are unable to subspeciate confidently on the basis of a single criterion. There was no relationship between the pattern of reactivity with the three MAbs, 179.1, 179.3 and 180.1 , and the reduction of nitrate, hence with the subspecies.

Of the individual MAbs, 180.1 reacted with 34 $(92 \%)$ of the 37 strains and shows the greatest potential for use in diagnostic tests. The sensitivity of the individual antibodies may be higher when they are used directly on vaginal smears or on freshly isolated organisms. It is essential in characterisation studies such as these that the organisms are purified, therefore all isolates we have used have been subcultured many times. We have shown that MAb 180.1 reacts with an epitope which is detected only on a subpopulation of each strain and is lost on subculture, either by selection of nonexpressing colonies or because expression has been switched off. This type of phase variation has been documented in several organisms including the loss of type-b capsule in Haemophilus influenzae (Hoiseth et al., 1985) and loss of piliation in $N$. gonorrhoeae (Sparling et al., 1986). It is also possible that the inability of the antibody to detect the epitope on some strains may be due to masking of the epitope by other outer-membrane material such as polysaccharide.

We have raised a single $\mathrm{MAb}$ with activity against the long curved rods, $M$. mulieris, and this reacted with only a small number of the clinical isolates tested. Although our strains were identified by the criteria described by Spiegel and Roberts (1984), the non-reactive strains may be atypical. Alternatively, antigenic heterogeneity in this species may limit the value of any single MAb.

The taxonomy of anaerobic curved rods and their inclusion in the genus Mobiluncus has been controversial, particularly the number of species and the separation of subspecies (Holst et al., 1982; Christiansen et al., 1984). Recently Vetere et al. (1987) 

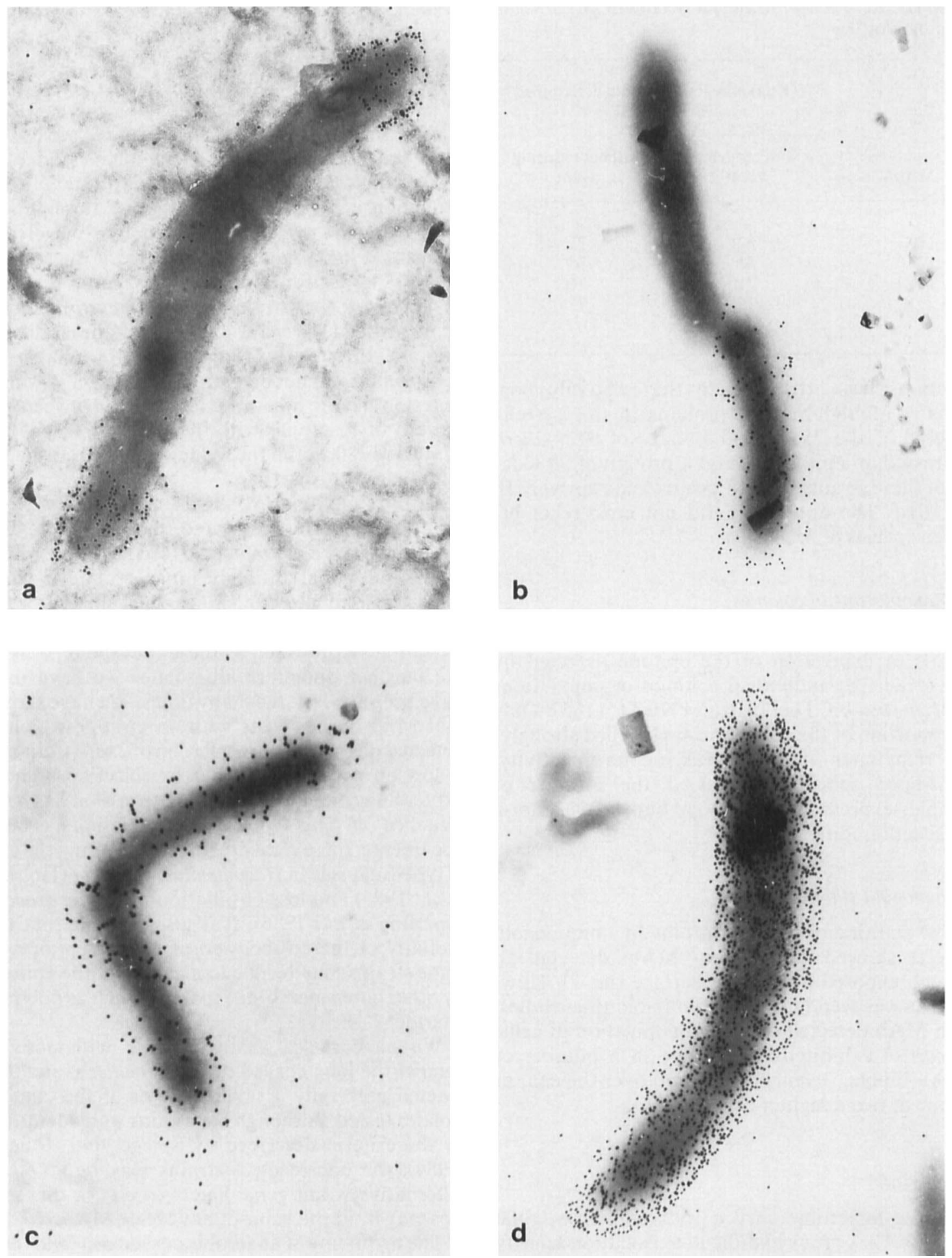

Fig. 2. Immunogold staining of $M$. curtisii subsp. curtisii NCTC 11656 with MAbs 179.1 (a), 179.3 (b) and 180.1 (c), and (d) of $M$. mulieris NCTC 11658 with MAb 181.1. 
have performed a large number of tests on isolates of Mobiluncus spp. They have described four groups of strains-typical short and long forms and atypical short and long forms. They have distinguished these groups by their reaction with Gram's strain, metronidazole susceptibility, ability to hydrolyse arginine and hippurate, and the presence of $\beta$-galactosidase. We also have encountered motile anaerobic curved rods in clinical material which could not be identified as Mobiluncus. All of these were non-reactive with these MAbs. However, it is not possible to determine whether any of the strains of $M$. mulieris that did not react with MAb 181.1, or our unclassified anaerobic curved rods, belong to the atypical groups described by Vetere et al. (1987) because we did not test for arginine hydrolysis.

If MAbs are to be used in studies to elucidate the role of Mobiluncus spp. in bacterial vaginosis, it is probable that several antibodies will be required to detect both the long and short forms. Hallen et al. (1987) have shown that of 90 strains of Mobiluncus spp. isolated from vaginal specimens, $44 \%$ were M. curtisii, $34 \%$ M. mulieris and in $21 \%$ both strains occurred together.

The MAbs we have raised react with epitopes which are exposed on the cell surface and appear to be subject to phase variation. The presence of the epitope detected by MAb 180.1 on surface-exposed proteins with mobilities corresponding to two distinct $\mathrm{Mr}$ values of 71 and $75 \mathrm{Kda}$ may be of interest in the pathogenicity of this organism. It is not known whether this represents the same epitope present on two different proteins or if it indicates a family of related proteins. In $N$. gonorrhoeae, the outer-membrane protein, PII, consists of a family of proteins which exhibit both phase and antigenic variation. These proteins are known to enhance the ability of gonococci to adhere to vaginal epithelial cells (Blake and Gotschlich, 1983). We now have preliminary results which show that MAb 180.1 inhibits the attachment of $M$. curtisii NCTC 11656 and 11657 to exfoliated vaginal epithelial cells in vitro. It is possible that this is an analogous situation to that of protein II of $N$. gonorrhoeae and that we have detected an outer-membrane protein family in $M$. curtisii that may have a role in colonisation.

We have raised MAbs to $M$. curtisii that, if used together, could aid the detection of these organisms in genital specimens. We have only a single $\mathrm{MAb}$ to $M$. mulieris which does not appear to be sufficiently cross-reactive for diagnostic purposes. If the true incidence of Mobiluncus spp. in bacterial vaginosis and in normal women is to be determined, good detection systems will be necessary to overcome the problems of culture. Although DNA probes have shown promising results, MAbs are more easily used in most laboratories.

\section{REFERENCES}

Blake M S, Gotschlich E C 1983 Gonococcal membrane proteins: speculation on their role in pathogenesis. Progress in Allergy 33: 298-313.

Christiansen G, Hansen E, Holst E, Christiansen C, Mårdh PA 1984 Genetic relationships of short and long anaerobic curved rods isolated from the vagina. In: Mårdh P-A, Taylor-Robinson $\mathrm{D}$ (eds) Bacterial vaginosis. Almqvist and Wiksell, Stockholm, pp 75-78.

Curtis A H 1913 A motile curved anaerobic bacillus in uterine discharges. Journal of Infectious Diseases 12: 165-169.

Durieux R, Dublanchet A 1980 Les "vibrions" anaérobies des leucorrhées I. Technique d'isolement et sensibilité aux antibiotiques. Médecine et Maladies Infectieuses 10: 109115 .

Galfrè G, Milstein C 1981 Preparation of monoclonal antibodies: strategies and procedures. Methods in Enzymology 73: 3-46.

Hallén A, Påhlson C, Forsum U 1987 Bacterial vaginosis in women attending STD clinic: diagnostic criteria and prevalence of Mobiluncus spp. Genitourinary Medicine 63: 386-389.

Hjelm E, Hallén A, Forsum U, Wallin J 1981 Anaerobic curved rods in vaginitis. Lancet 2 : $1353-1354$.

Hjelm E, Forsum U, Hallén A, Påhlson C, Wallin J 1984 Primary isolation of curved rods from women with vaginal discharge. In: Mårdh P-A, Taylor-Robinson D (eds)

Bacterial vaginosis. Almqvist and Wiksell, Stockholm, pp 113-116.

Holdeman L V, Cato E P, Moore W E C 1977 Anaerobe laboratory manual, 4th edn, Virginia Polytechnic Institute and State University, Blacksburg, VA, USA.

Hoiseth S K, Connelly C J, Moxon E R 1985 Genetics of spontaneous high-frequency loss of $\mathrm{b}$ capsule expression in Haemophilus influenzae. Infection and Immunity 49:389-395.

Holst E, Skarin A, Mårdh P-A 1982 Characteristics of anaerobic comma-shaped bacteria recovered from the female genital tract. European Journal of Clinical Microbiology 1 : 310-316.

Laemmli U K 1970 Cleavage of structural proteins during the assembly of the head of bacteriophage T4. Nature 227:680685.

Lowry O H, Roseborough N J, Farr A L, Randall R J 1951 Protein measurement with the folin phenol reagent. Journal of Biological Chemistry 193: 265-275.

Moore B 1954 Observations on a group of anaerobic vaginal vibrios. Journal of Pathology and Bacteriology 67: 461-473.

Phillips I, Taylor E 1982 Anaerobic curved rods in vaginitis. Lancet 1:221.

Roberts M C, Hillier S L, Schoenkneckt F D, Holmes K K 1985 Comparison of Gram stain, DNA probe and culture for the identification of species of Mobiluncus in female genital specimens. Journal of Infectious Diseases 152: 74-77.

Skarin A, Mårdh P-A 1982 Comma-shaped bacteria associated with vaginitis. Lancet 1 : $342-343$.

Sparling P F, Cannon J G, So M 1986 Phase and antigenic 
variation of pili and outer membrane protein II of Neisseria gonorrhoeae. Journal of Infectious Diseases 153: 196-201.

Spiegel C A, Eschenbach D A, Amsel R, Holmes K K 1983 Curved anaerobic bacteria in bacterial (nonspecific) vaginosis and their response to antimicrobial therapy. Journal of Infectious Diseases 148: 817-822.

Spiegel C A, Roberts M 1984 Mobiluncus gen. nov., Mobiluncus curtisii subsp. curtisii sp nov., Mobiluncus curtisii subsp. holmesii subsp. nov., and Mobiluncus mulieris sp nov., curved rods from the human vagina. International Journal of Systematic Bacteriology 34: 177-184.

Sprott M S, Pattman R S, Ingham H R, Short G R, Narang H
K, Selkon J B 1982 Anaerobic curved rods in vaginitis. Lancet $1: 54$.

Sprott M S et al. 1983 Characteristics of motile curved rods in vaginal secretions. Journal of Medical Microbiology 16: 175182.

Towbin H, Staehelin T, Gordon J 1979 Electrophoretic transfer of proteins from polyacrylamide gels to nitrocellulose sheets. Procedure and some applications. Proceedings of the National Academy of Sciences of the USA 76: 4350-4354.

Vetere A, Borriello S P, Fontaine E, Reed P J, Taylor-Robinson D 1987 Characterisation of anaerobic curved rods (Mobiluncus spp.) isolated from the urogenital tract. Journal of Medical Microbiology 23 : 279-288. 